\title{
Computed tomography sheds new light on the affinities of the enigmatic euarthropod Jianshania furcatus from the early Cambrian Chengjiang biota
}

Yu Liu ${ }^{1,2^{*}+}$, Javier Ortega-Hernández ${ }^{3^{*}+}$, Hong Chen ${ }^{1,2}$, Huijuan Mai ${ }^{1,2}$, Dayou Zhai ${ }^{1,2}$ and Xianguang Hou ${ }^{1,2}$

\begin{abstract}
Background: The Chengjiang biota is one of the most species-rich Cambrian Konservat-Lagerstätten, and preserves a community dominated by non-biomineralized euarthropods. However, several Chengjiang euarthropods have an unfamiliar morphology, are extremely rare, or incompletely preserved.

Results: We employed micro-computed tomography to restudy the enigmatic euarthropod Jianshania furcatus. We reveal new morphological details, and demonstrate that the specimens assigned to this species represent two different taxa. The holotype of J. furcatus features a head shield with paired anterolateral notches, stalked lateral eyes, and an articulated tailspine with a bifurcate termination. The other specimen is formally redescribed as Xiaocaris luoi gen. et sp. nov., and is characterized by stalked eyes connected to an anterior sclerite, a subtrapezoidal head shield covering three small segments with reduced tergites, a trunk with 15 overlapping tergites with a well-developed dorsal keel, and paired tail flukes.

Conclusions: The presence of antennae, biramous appendages with endopods composed of 15 articles, and multiple appendage pairs associated with the trunk tergites identify $X$. luoi nov. as a representative of Fuxianhuiida, an early branching group of stem-group euarthropods endemic to the early Cambrian of Southwest China. X. Iuoi nov. represents the fifth fuxianhuiid species described from the Chengjiang biota, and its functional morphology illuminates the ecological diversity of this important clade for understanding the early evolutionary history of euarthropods.
\end{abstract}

Keywords: Euarthropoda, Konservat-Lagerstätte, Exceptional preservation, Pyritization, Fuxianhuiid, Computed tomography

\footnotetext{
* Correspondence: yu.liu@ynu.edu.cn; jortegahernandez@fas.harvard.edu

${ }^{\dagger}$ Yu Liu and Javier Ortega-Hernández contributed equally and share co-first authorship of this manuscript.

${ }^{1}$ Yunnan Key Laboratory for Palaeobiology, Institute of Palaeontology,

Yunnan University, Kunming 650500, China

${ }^{3}$ Museum of Comparative Zoology and Department of Organismic and

Evolutionary Biology, Harvard University, 26 Oxford Street, Cambridge, MA

02138, USA

Full list of author information is available at the end of the article
}

(c) The Author(s). 2020 Open Access This article is licensed under a Creative Commons Attribution 4.0 International License, which permits use, sharing, adaptation, distribution and reproduction in any medium or format, as long as you give appropriate credit to the original author(s) and the source, provide a link to the Creative Commons licence, and indicate if changes were made. The images or other third party material in this article are included in the article's Creative Commons licence, unless indicated otherwise in a credit line to the material. If material is not included in the article's Creative Commons licence and your intended use is not permitted by statutory regulation or exceeds the permitted use, you will need to obtain permission directly from the copyright holder. To view a copy of this licence, visit http://creativecommons.org/licenses/by/4.0/ The Creative Commons Public Domain Dedication waiver (http://creativecommons.org/publicdomain/zero/1.0/) applies to the data made available in this article, unless otherwise stated in a credit line to the data. 


\section{Background}

The Yangtze Platform in China contains several Cambrian localities that have produced critical insights into the origin and early evolution of complex organisms, as well as the ecological dynamics of some of the earliest animal-dominated ecosystems [1, 2]. In addition to a substantial shelly fossil record [3, 4], this large area is world-renowned due to the occurrence of numerous sites containing soft-tissue fossil preservation, or Konservat-Lagerstätten, that have fundamentally illuminated the extinct biodiversity at the time in a variety of marine settings during the Cambrian Explosion. Exceptional deposits in the Yangtze Platform are geographically and stratigraphically widespread for the Cambrian, with sites ranging from Stage 3 (e.g. Chengjiang, Qingjiang, Xiaoshiba; see [2, 3, 5, 6], to Stage 4 (e.g. Balang, Guanshan, Shipai; see [7-9]), Wuliuan (Kaili; see [10]) and even Furongian (Guole; see [11]). However, the Chengjiang biota of the Yu'anshan Member, Chiungchussu Formation, of Yunnan Province distinguishes itself from other fossiliferous localities in China by its unparalleled species richness, quality of fossil preservation, abundance and geographical coverage $[3,12]$, to the extent that it represents the only confirmed Tier 1 Burgess Shale-type deposit in the Yangtze Platform to date [13]. Since its discovery in 1984, the Chengjiang biota has been a focal point of intense palaeobiological scrutiny due to the abundance of non-biomineralized macrofossils resulting from organic carbon preservation and decay-induced pyritization by sulphur-reducing bacteria [14, 15]. Similar to other major Cambrian Konservat-Lagerstätten around the world [16-20], the metazoan community preserved in Chengjiang is dominated by euarthropods in terms of species richness and abundance, which in addition to a rich trilobite fauna also includes several dozens of non-biomineralized taxa $[12,21,22]$. The superb quality of soft-tissue preservation in Chengjiang fossils has produced deep insights into the biology of Cambrian euarthropods, informing about important aspects of their internal anatomy such as the digestive tract [23-25] and nervous system [26-28], as well as insights into their behavior and ecology [29-31]. Arguably one of the most remarkable contributions of Chengjiang euarthropods has been the availability of detailed morphological data on the ventral appendages of disparate groups that illuminate the functional morphology and higher phylogenetic affinities of these organisms [29, 32-34]. More recently, the application of X-ray based computed tomography has - somewhat metaphorically opened a new dimension to the study of Chengjiang euarthropods [35]. Computed tomography allows to recover minute and detailed information on the three-dimensional organization of the exoskeleton and appendages that would normally be concealed within the rock matrix, without the need for mechanical preparation that would risk damaging the specimens [36-40]. One of the main advantages of this approach is that it allows restudying poorly known taxa that are extremely rare, and hence precious within the Chengjiang biota. Such is the case of Jianshania furcatus [41], Fig. 1 described from the Ercaicun section in Haikou, Kunming. Originally regarded as a problematic euarthropod of uncertain affinity, the overall exoskeletal anatomy, appendicular organization and significance of Jianshania have remained completely overlooked for more than 20 years, with the exception of cursory mentions in a few studies exploring taxonomic diversity of soft-bodied fossils in Cambrian deposits in South China $[3,12,16,22,42]$. Here, we employ microCT to reveal previously unknown details of the dorsal exoskeleton and ventral appendage organization of Jianshania furcatus, and demonstrate that the type material actually encompasses two distinct species that contribute towards a better understanding of the diversity of Cambrian euarthropods in the Chengjiang biota.

\section{Results}

\section{Systematic Palaeontology}

Euarthropoda Lankester, 1904 [43].

Deuteropoda Ortega-Hernández, 2016 [44].

Fuxianhuiida Bousfield, 1995 [45].

\section{Constituent taxa}

Liangwanghania biloba [46]; Shankouia zhenghei [47]; Fuxianhuiidae [21] (including Fuxianhuia protensa [48]; Fuxianhuia xiaoshibaensis [5]; Guangweicaris spinatus [49]; Xiaocaris luoi nov.); Chengjiangocarididae [21] (including Chengjiangocaris longiformis [49, 50]; Chengjiangocaris kunmingensis [5]; Alacaris mirabilis [51]). Modified from [51].

\section{Diagnosis}

Euarthropods with a subtrapezoidal head shield articulated with an anterior sclerite carrying stalked compound eyes. Trunk with broadly overlapping tergites that taper in width posteriorly. Variable number of anteriormost reduced tergites, completely or partially concealed under head shield. Pre-oral first appendage pair antenniform, composed of up to 20 articles. Para-oral second appendage robust and uniramous, consisting of three articles with acute termination. Sclerotized hypostome covering mouth opening and proximal bases of second appendage pair. Where known, hypostome with lateral wing-like extensions, and median notched posterior margin. Post-oral trunk appendages biramous, with a homonomous construction. Each of the anteriormost reduced tergites corresponds to one pair of appendages, while each normal trunk tergite corresponds to up to four biramous appendage pairs. Endopod consisting of 


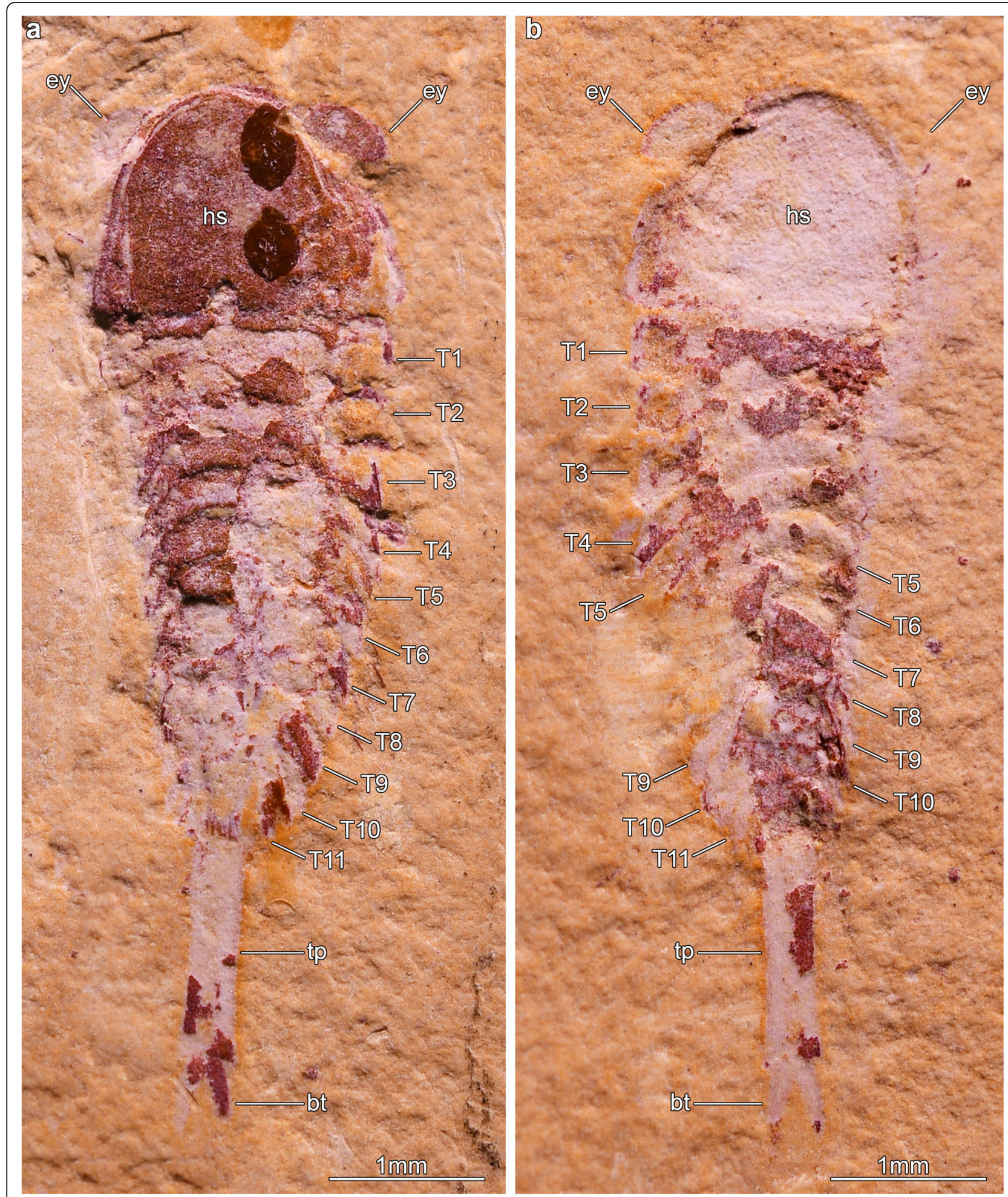

Fig. 1 Jianshania furcatus, from the Ercaicun section of Haikou, Cambrian (Stage 3) Chengjiang biota. a Part of holotype (Hz-f-6-307a), complete specimen preserved in dorsal-ventral aspect, photographed under cross-polarized light. See also [41], Plate 7, Fig. 4. b Counterpart of holotype (Hz-f-6-307b), photographed under cross-polarized light 
at least 12 articles. Differentiated gnathobasic protopodite confirmed in some species. Exopod oval-shaped, fringed with short marginal setae. Tailspine conical or paddle-shaped, associated with paired tail flukes. Modified from [51].

\section{Remarks}

Fuxianhuiids have some unusual traits that can cause confusion when describing their preserved morphology. The organization of the metameric units that constitute the body offers clear evidence of dorsoventral segmental mismatch between the exoskeleton, appendages, and even the internal organs $[5,21,25,31,51-55]$. The fossilized fuxianhuiid body consists of a variable number of broadly articulating tergites (i.e. dorsal exoskeletal plates), and these can be associated with between one and four pairs of ventral biramous appendages depending on their position within the trunk, as well as the taxon itself. For instance, whereas the anterior small segments with reduced tergites found underneath the head shield carry only one pair of appendages in all fuxianhuiids, the full-sized tergites that constitute most of the trunk are associated with two appendage pairs in Fuxianhuia [21, 31] and Guangweicaris [52], and up to four appendage pairs in Chengjiangocaris [5] and Alacaris [51], implying the presence of multiple segmental units per tergite. External segmental mismatch has been observed between the number of dorsal tergites and ventral appendage pairs; however, the segmental organization of sternites (i.e. ventral exoskeletal plates) is uncertain, as these structures are not known from any fuxianhuiid described to date. Because of this derived condition, we describe the preserved exoskeletal trunk organization of fuxianhuiids based on the number and morphology of the tergites for clarity, and only make reference to the underlying segments in cases where there is no evidence for dorsoventral mismatch, such as the anterior small segments underneath the head shield, or the appendageless posterior trunk.

Fuxianhuiidae Hou and Bergström, 1997 [21].

\section{Diagnosis}

Fuxianhuiids with subtrapezoidal head shield typically wider (trans.) than long (sag.), and covering (completely or partially) three small anteriormost trunk segments with reduced tergites in life position. Trunk subdivided into anterior appendage-bearing part with welldeveloped expanded tergopleurae encompassing between 50 to $60 \%$ of trunk length (sag.), and posterior appendage-less part with narrowed segments. Endopods of biramous appendages may feature rounded termination and no endites, or acute termination with developed ventral endites. Modified from [51, 52].

\section{Remarks}

Our updated diagnosis of Fuxianhuiidae incorporates new observations of Xiaocaris luoi nov. from the present study, as well as the recent re-descriptions of Guangweicaris spinatus from the Cambrian (Stage 4) Guanshan biota $[52,53]$. In this context, the unique characters that unite Fuxianhuiidae include the three small anteriormost tergites underneath the head shield, and a trunk subdivided in terms of its tergite morphology and presence of biramous appendages. Other relevant adjustments to the diagnosis of Fuxianhuiidae include: 1) the recognition that the head shield in all members of this group is wider than long, particularly when compared to that of Chengjiangocarididae [21] Hou and Bergström, 1997, in which the length/width ratio is approximately $1: 1 ; 2$ ) the dimensions of the anterior tergites with expanded tergopleurae, associated with appendage-bearing segments, comprise between 50 to $60 \%$ of the trunk length (sag.), whereas the appendage-bearing region may comprise up to $80 \%$ of the trunk length (sag.) in Chengjiangocarididae $[5,21,51]$; 3) the fact that the endopod morphology is variable between Fuxianhuia species (i.e. rounded tips and no endites) when compared with Guangweicaris (acute termination with ventral endites). It should be noted that taxa falling outside these clades, namely Shankouia zhenghei [47], and Liangwangshania biloba [46], also have a head shield that is wider than long, but these two taxa lack other features that define Fuxianhuiidae, namely the presence of three small segments with reduced tergites and the strong differentiation of the trunk. Chen and colleagues recently suggested the status of Shankouia as a junior synonym, and potential sexual dimorph, of Liangwangshania [54]. Regardless of whether these taxa represent one or two different species, their exoskeletal organization is distinctive enough to avoid confusion with members of either Fuxianhuiidae or Chengjiangocarididae. For instance, Liangwangshania/Shankouia feature a fused paddle-shaped tailspine, and their tergites with expanded tergopleurae extend to approximately $90 \%$ of the trunk length (sag.), compared with the 50\% (e.g. Guangweicaris) to $60 \%$ (Fuxianhuia) observed in Fuxianhuiidae.

\section{Xiaocaris gen. nov. Etymology}

Derived from the Chinese Xiǎo (小) meaning small, as this represents the smallest fuxianhuiid species to date in terms of known body size, and the Latin caris, meaning shrimp, a common suffix used to denote euarthropod affinities.

\section{Type species}

Xiaocaris luoi nov. 


\section{Diagnosis}

Small fuxianhuiid with boomerang-shaped head shield with deeply procurved posterior margin. Head shield associated with prominent eye-bearing anterior sclerite. Trunk divided into an appendage-bearing anterior region with nine tergites, and an appendage-less posterior part with six narrowed segments. First three segments small relative to rest of trunk, with reduced tergites partially covered by head shield. Last appendage-less segment carrying a pair of terminal tail flukes. Antennae elongate, consisting of at least 18 articles. Endopod consisting of at least 15 proximal articles each bearing a well-developed spine-like endite, and one acute terminal article. Exopod with short but densely packed marginal setae.

Xiaocaris luoi nov.

1999 Jianshania furcatus gen. et sp. nov. Luo et $\mathrm{Hu},-$ [41] Plate 8, Fig. 1a, b.

2002 Jianshania furcatus (mistyped as Jianshania forficula) - [42] Plate 6, Fig. 3a, b.

\section{Etymology}

Named after Prof. Huilin Luo, in recognition of his work on the Chengjiang biota and the discovery of the holotype of this species (He-f-6-5-63/64), and generously facilitating access to the material for its formal restudy.

\section{Type material}

He-f-6-5-63 (holotype, part) and He-f-6-5-64 (holotype, counterpart) of a complete individual (Figs. 2, 3). The specimen was identified as Jianshania furcatus in the original description of that species, along with the holotype (Fig 1). Chen and colleagues included part and counterpart of the same specimen in their Plate 6, Fig. $3 \mathrm{a}, \mathrm{b}$ and noted that He-f-6-5-64 was the holotype of Jianshania furcatus [42]. However, this was incorrect, because the holotype of $J$. furcatus had already been designated as Hz-f-6-307 in the original description [41].

\section{Locality and horizon}

Ercaicun section in Haikou, Kunming, China. Yu'anshan Member, Chiungchussu Formation (Cambrian Stage 3), Eoredlichia-Wutingaspis trilobite biozone [12].

\section{Diagnosis}

As for genus.

\section{Description}

The only known specimen, He-f-6-5-63/64, designated as holotype herein, represents a completely articulated individual preserved in dorsal-ventral aspect, with a total length (sag.) of $20.5 \mathrm{~mm}$, and a maximum width (trans.) of $5 \mathrm{~mm}$, measured at the level of the fourth trunk tergite. The dorsal exoskeleton consists of a broad, semicircular anterior sclerite associated with stalked lateral eyes, and articulated to the anterior edge of a boomerang-shaped head shield (Figs. 2, 3). The head shield has an approximately 1:2 maximum length/width ratio, and features rounded lateral angles, and a deeply procurved posterior edge that partially covers at least three anteriormost small trunk tergites underneath (Fig. 4a, b). The tergites of the small anterior segments have rounded pleurae, and also a gently procurved posterior margin. The trunk presents three anteriormost small segments and additional 12 broadly overlapping tergites that progressively narrow in width (trans.) towards the posterior end of the body (Figs. 2, 3, 4). The fourth to ninth trunk tergites comprise approximately half of the total trunk length (sag.); they are characterized by a subtrapezoidal outline, have expanded tergopleurae with straight lateral margins and acute lateroposterior tips, and an anteriorly reflexed posterior margin (Figs. 2, 3). With the exception of the anteriormost small segments, the remaining trunk tergites feature a well-developed dorsal keel that conveys an elevated subtriangular transverse profile to the body (Figs. 2a; 4a-c). The dorsal keels of successive tergites telescope with each other (Fig. 4a, b). The tenth to fifteenth tergites, corresponding to the appendage-less posterior trunk have a subrectangular outline with a longer sagittal axis, are considerably narrower due to the absence of expanded tergopleurae, and terminate in a pair of tail flukes (Figs. 2d; 4c, d). The presence of a discrete telson cannot be resolved due to preservation.

Micro-CT reveals exceptional details of the ventral anatomy concealed within the rock matrix (Figs. 3, 4, 5). He-f6-5-63 preserves the remains of elongate antennae composed of at least 18 articles, and attached close to the anterior edge of the head shield (Figs. 3a, b; 5a). It is possible to observe a fragmentary hypostome behind the antennae, as indicated by the presence of a bilobed posterior margin similar to that observed in other fuxianhuiids (Fig. 2d) [51]. The median position of the hypostome within the head shield suggests a slight degree of posterior displacement during burial. He-f-6-5-63 shows no other traces of preserved head appendages. Each of the three anteirormost small tergites corresponds to one pair of biramous appendage, whereas the following six tergites are associated with four pairs of biramous appendages that are densely packed, and slightly decrease in size towards the posterior end (Figs. 3b; 4d; 5b). There is no evidence for appendages associated with tergites 10-15. The endopod is composed of at least 15 articles that taper distally and bear a single welldeveloped triangular endite (Figs. 3b; 5b, c). The terminal claw is small and has an acute termination. Other than the presence of more robust endites towards the base of the appendage (arrowheads in Fig. 5b, c), there is no clear evidence for the presence of a differentiated protopodite in 

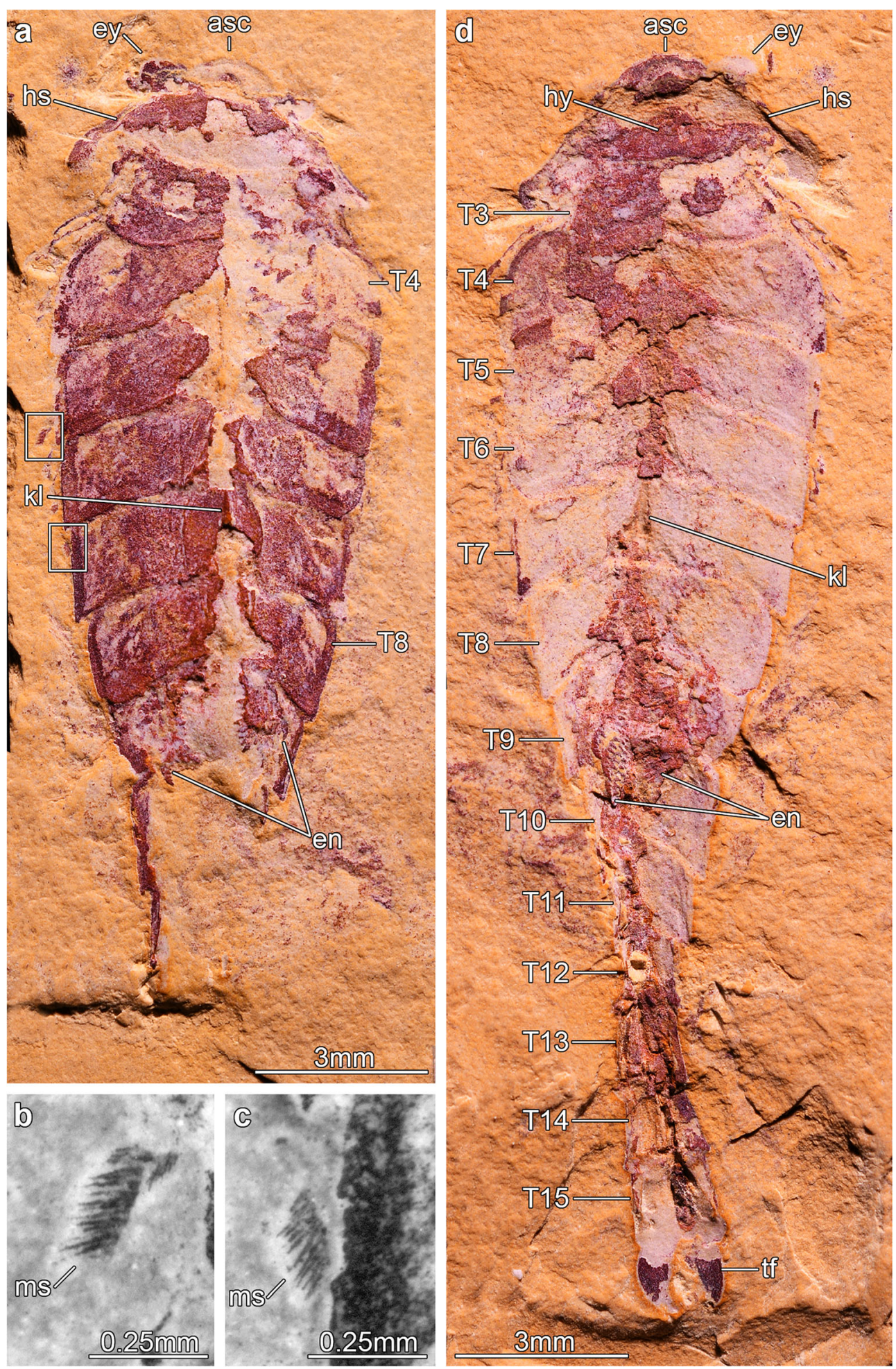

Fig. 2 The fuxianhuiid Xiaocaris luoi nov. from the Ercaicun section of Haikou, Cambrian (Stage 3) Chengjiang biota. a Holotype (He-f-6-5-63), part of complete specimen preserved in dorsal-ventral aspect and photographed under cross-polarized light. b Magnification of an exopod underneath the fifth trunk tergite of He-f-6-5-63 showing marginal setae, photographed under fluorescent light. c Magnification of an exopod underneath the seventh trunk tergite of He-f-6-5-63 showing marginal setae, photographed with fluorescent light. d Holotype (He-f-6-5-64), counterpart photographed under cross-polarized light 


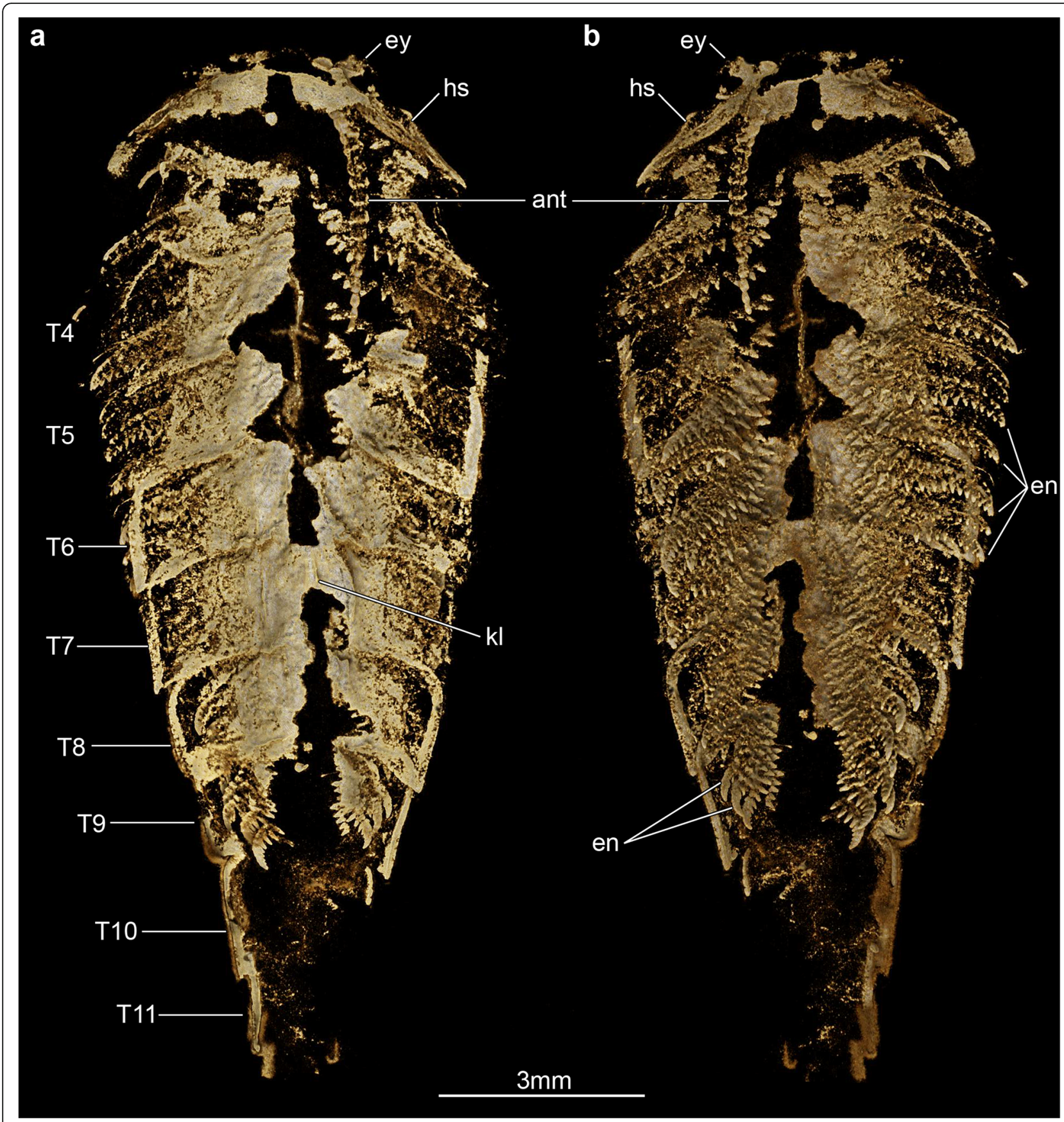

Fig. 3 Overall three-dimensionally preserved exoskeletal morphology of Xiaocaris luoi nov. part (He-f-6-5-63, see also Fig. 2a). a Tomographic model of whole specimen in dorsal view. $\mathbf{b}$ Tomographic model of whole specimen in ventral view

the trunk appendages. Densely arranged bundles of marginal spines preserved on the left side of He-f-6-5-63 demonstrate the presence of trunk exopods (Fig. 2b, c), but the structure of the flap is not preserved in this specimen.

\section{Remarks}

Luo and colleagues originally assigned the specimen He-f6-5-63/64 (Xiaocaris luoi nov. holotype; Fig. 2) to
Jianshania furcatus (holotype: Hz-f-6-307, Fig. 1) [41]. Specimen He-f-6-5-63/64 was subsequently refigured by other workers under the incorrect name Jianshania forficula (nomen nudum) [42], but specimen Hz-f-6-307 was not illustrated again until now. Although Jianshania has been mentioned in various publications addressing the taxonomic composition of the Chengjiang biota, or comparisons between palaeobiogeographic patterns of soft- 


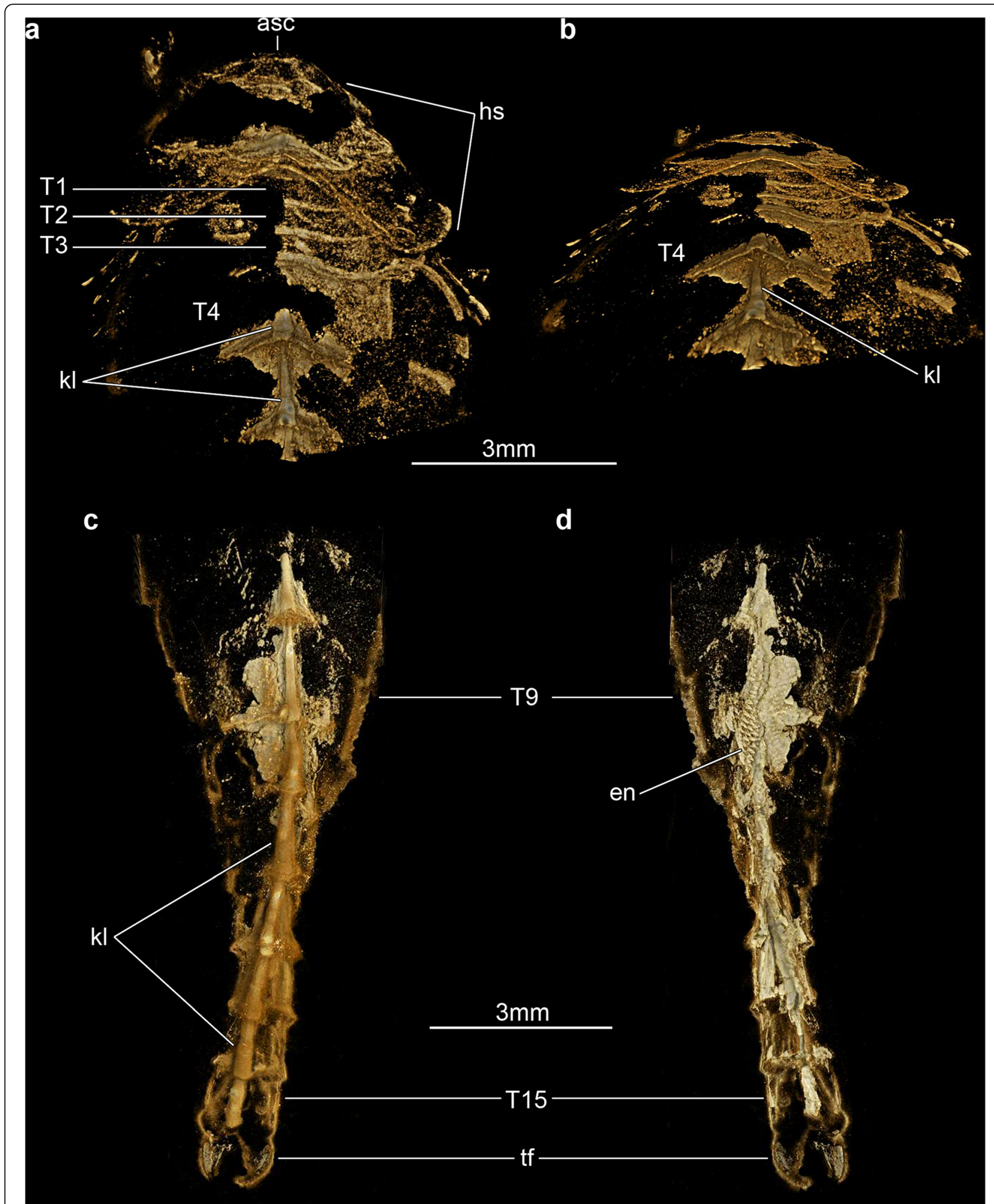

Fig. 4 Three-dimensionally preserved exoskeletal morphology of Xiaocaris luoi nov. counterpart (He-f-6-5-64, see also Fig. 2d). a Tomographic model of anterior region in ventral view. $\mathbf{b}$ Same as panel (a) but with 60-degree inclination away from the observer. c Tomographic model of posterior trunk region in dorsal view. d Same as panel (c) but in ventral view 


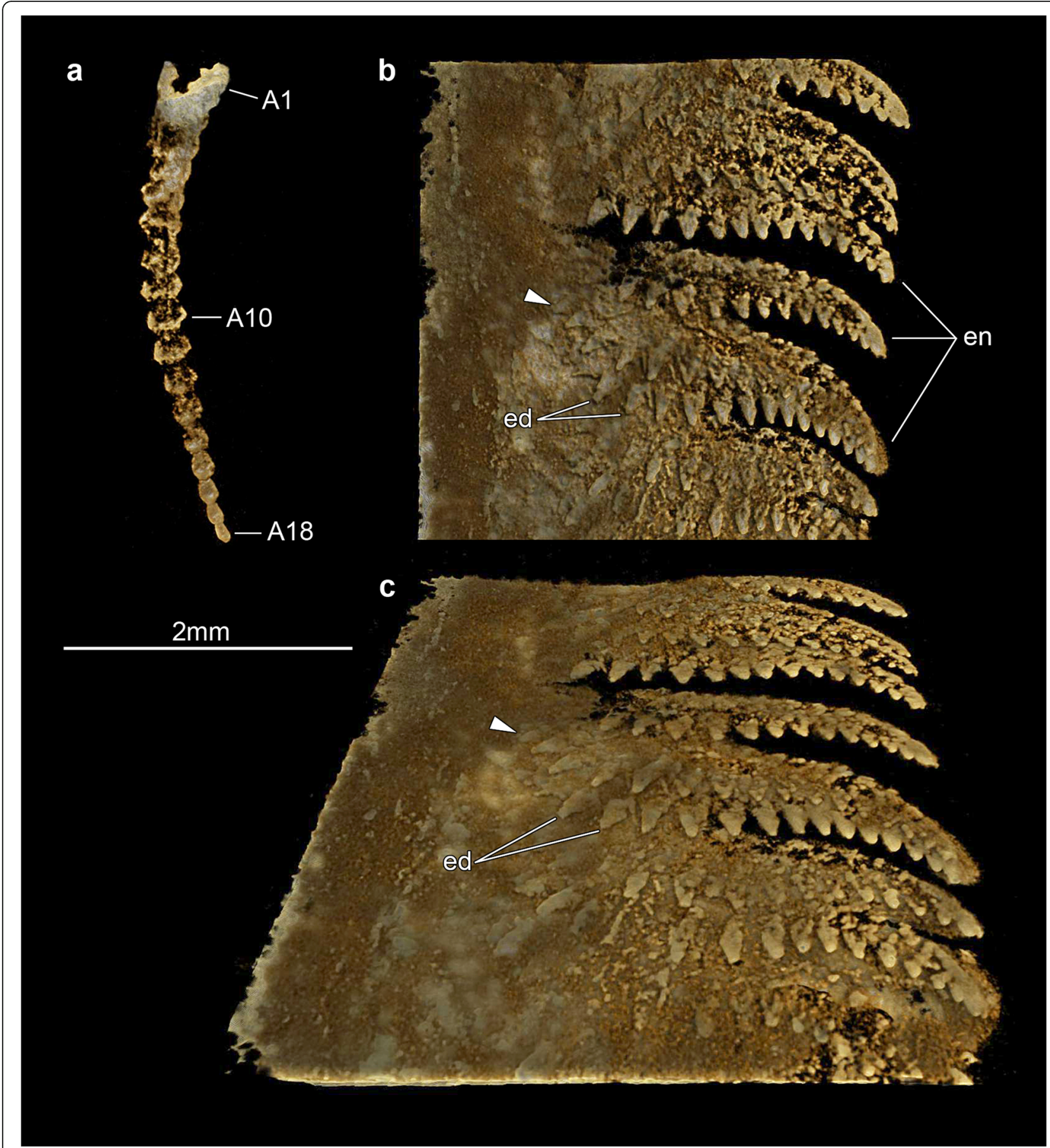

Fig. 5 Appendage organization of Xiaocaris luoi nov. part (He-f-6-5-63). a Tomographic model of antenna in ventral view. b Tomographic model of trunk appendage series underneath fifth and sixth trunk tergites in ventral view. Arrowhead indicates position of most basal observable article. c Same as panel (b) but with 60-degree inclination away from the observer

bodied euarthropods during the Cambrian $[3,12,16,22$, 42], none of these studies addressed the morphology of the type material. Restudy of these specimens, together with the new insights on the exoskeletal organization of He-f-6-5-63/64 possible through micro-CT techniques, demonstrates that the material assigned to Jianshania furcatus belongs to two fundamentally different euarthropod taxa. Other than a superficial resemblance in terms of overall body shape and proportions, micro- $\mathrm{CT}$ indicates that He-f-6-5-63/64 can be assigned to Fuxianhuiida based 
a

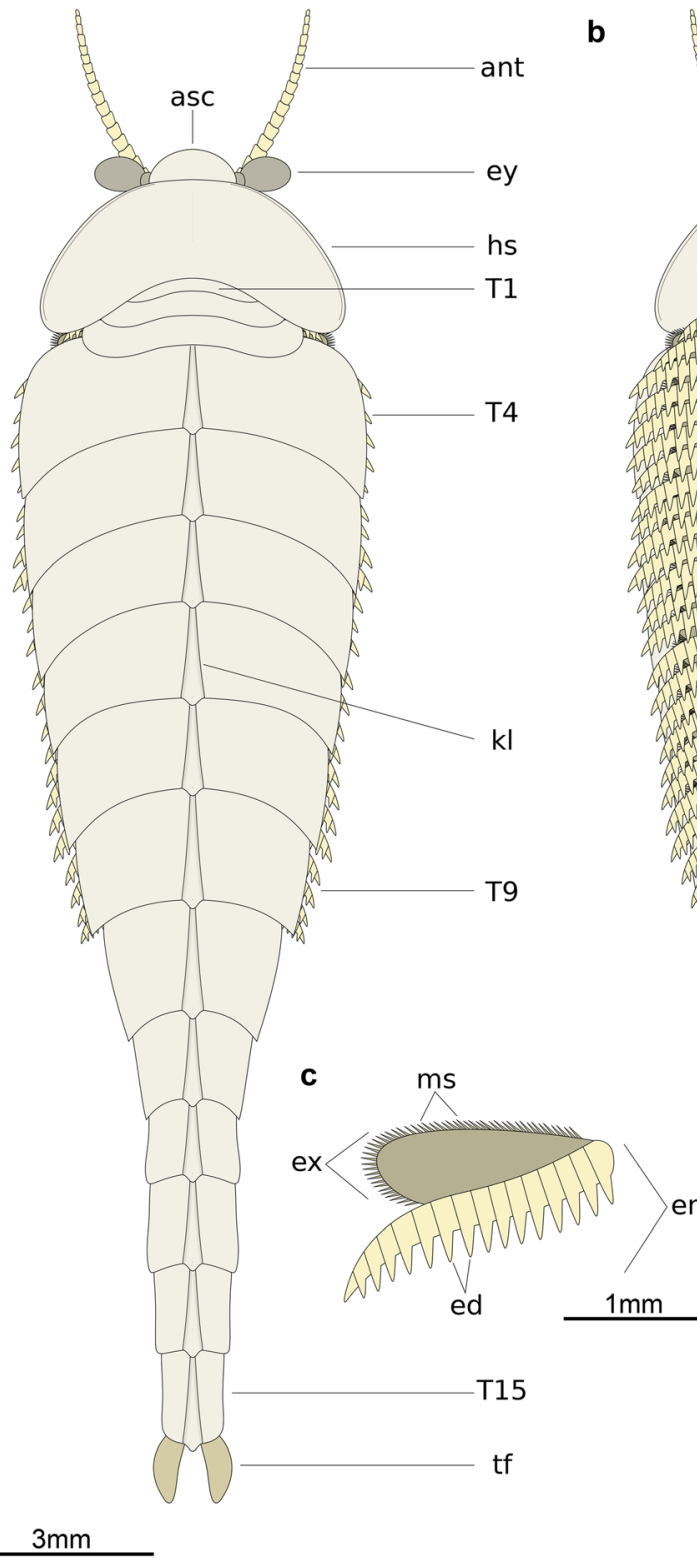

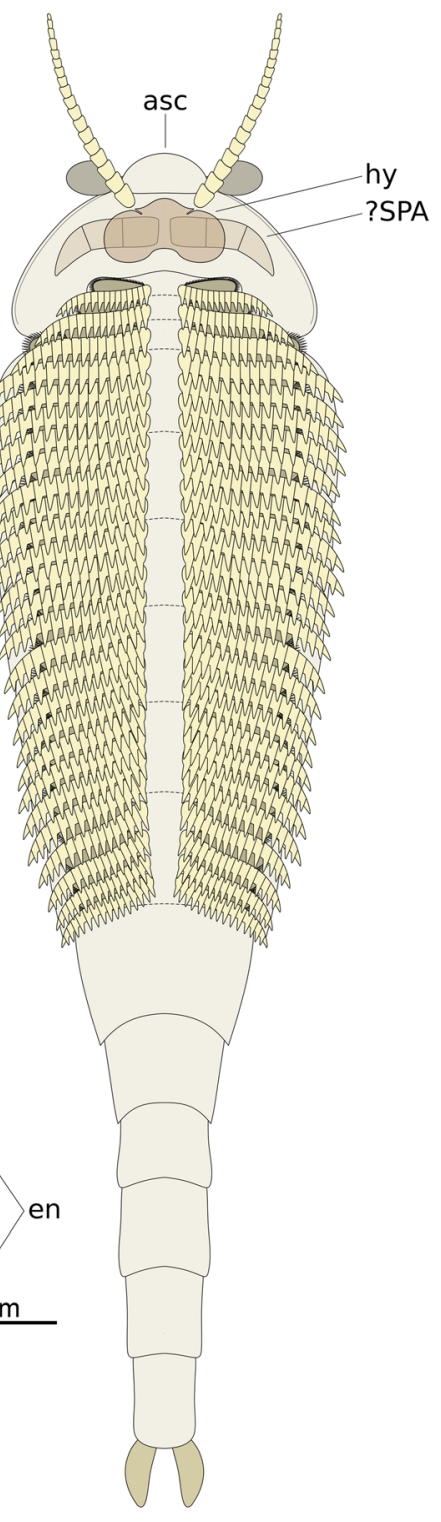

SPA

Fig. 6 Morphological reconstruction of Xiaocaris luoi nov. a Dorsal view. b Ventral view; note that the anterior morphology of the hypostome, presence of specialized post-antennal appendages (SPA) and exopod structure are extrapolated from those of other better-known fuxianhuiids (see [51]). Dashed lines indicate position of posterior margin of tergites relative to ventral biramous appendages. c Biramous trunk appendage

on several diagnostic exoskeletal characters, most notably the presence of small trunk tergites under the head shield articulated to an eye-bearing anterior sclerite (Figs. 2, 3). These features are entirely lacking in the holotype of Jianshania furcatus (Hz-f-6-307, Fig. 1), which is characterized by a semicircular head shield with possible anterolateral notches accommodating large bulbous eyes, a straight posterior margin of the head shield, a trunk with 11 segments whose tergites taper and curve posteriorly, an undivided tailspine approximately one third the total body length (sag.) with one distal articulation, and a bifid termination.
Hz-f-6-307 further differs from He-f-6-5-63/64 in the absence of an anterior sclerite, a lower trunk segment count, different tergite morphology without a dorsal keel, and presence of a tailspine rather than a narrowed trunk. These discrepancies support the assignment of He-f-6-563/64 as the holotype of Xiaocaris luoi nov, whereas Hz-f6-307 remains as the holotype of Jianshania furcatus. We defer a more comprehensive reappraisal of the exoskeletal and ventral morphology of Hz-f-6-307 pending the availability of appropriately detailed micro-CT data currently under preparation. 


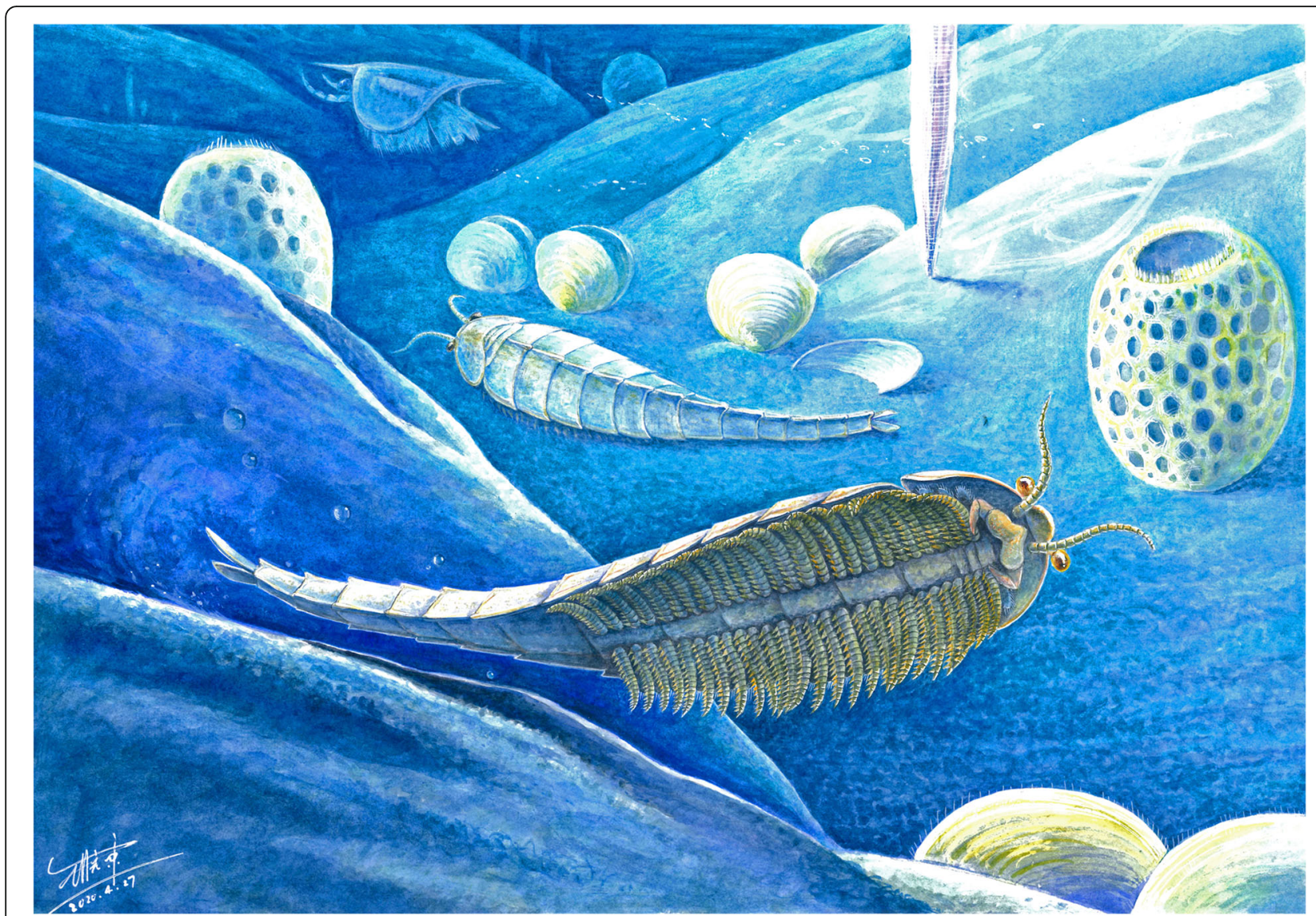

Fig. 7 Morphological reconstruction of the fuxianhuiid Xiaocaris luoi nov. from the early Cambrian Chengjiang biota of South China. Artist: Mr. Xiaodong Wang

\section{Discussion}

\section{Xiaocaris luoi nov. as a member of Fuxianhuiidae}

The exoskeletal and appendicular organization of Xiaocaris luoi nov. unequivocally identifies it as a representative of Fuxianhuiida [45] as presently defined (see also $[5,22,51,53,54])$, particularly given the diagnostic anteriormost reduced tergites under the head shield connected with an eye-bearing anterior sclerite [56], and the derived presence of multiple appendage pairs per trunk tergite, which also have endopods with over a dozen articles. Furthermore, the presence of at least three small tergites and a trunk consisting of an appendage-bearing anterior part, and an appendage-less, narrower posterior part, also represent diagnostic features of Fuxianhuiidae ([21], Figs. 6, 7, 8). In this context, Xiaocaris nov. increases the species richness and morphological diversity for Fuxianhuiidae, and further contributes towards reconstructing the relationships within this group.

Xiaocaris nov. most closely resembles Guangweicaris spinatus from the Guanshan biota [49, 52, 53, 57]. Both species share 15 trunk tergites with a single series of well-developed median tergal processes expressed as the strong dorsal spines throughout the trunk of G. spinatus, and the keel observed in Xiaocaris luoi nov. (Fig. 4). The structure of the endopods in these two taxa has an acute distal termination and well-developed ventral endites (albeit more robust in Xiaocaris luoi nov.) (Figs. 3; 5b, c) $[52,53]$, both of which contrast with the blunt endopods found in Fuxianhuia species [5, 21, 58], or the almost conical endopods of chengjiangocaridids [51, 59]. In the context of Fuxianhuiidae, Xiaocaris nov. also resembles Guangweicaris in having head shields with an approximately 1:2 length/width ratio, the subtrapezoidal outline of the tergites on the appendage-bearing part of the trunk, tergopleurae with straight lateral margins and subrectangular tergites of the appendage-less trunk region, all of which differ from the much shorter (sag.) head shield (1:4 length/width) and tergopleurae of Fuxianhuia $[5,21,58]$. Xiaocaris nov. is distinguished from Guangweicaris based on several characters, including: a deeper posterior notch in the head shield (Fig. 4a, b); the allocation of trunk tergites (nine appendage-bearing and six appendage-less segments in Xiaocaris nov. versus eight appendage-bearing and seven appendage-less ones in Guangweicaris) (Fig. 2); lack of developed tergal spines on the trunk; presence of four appendage pairs 


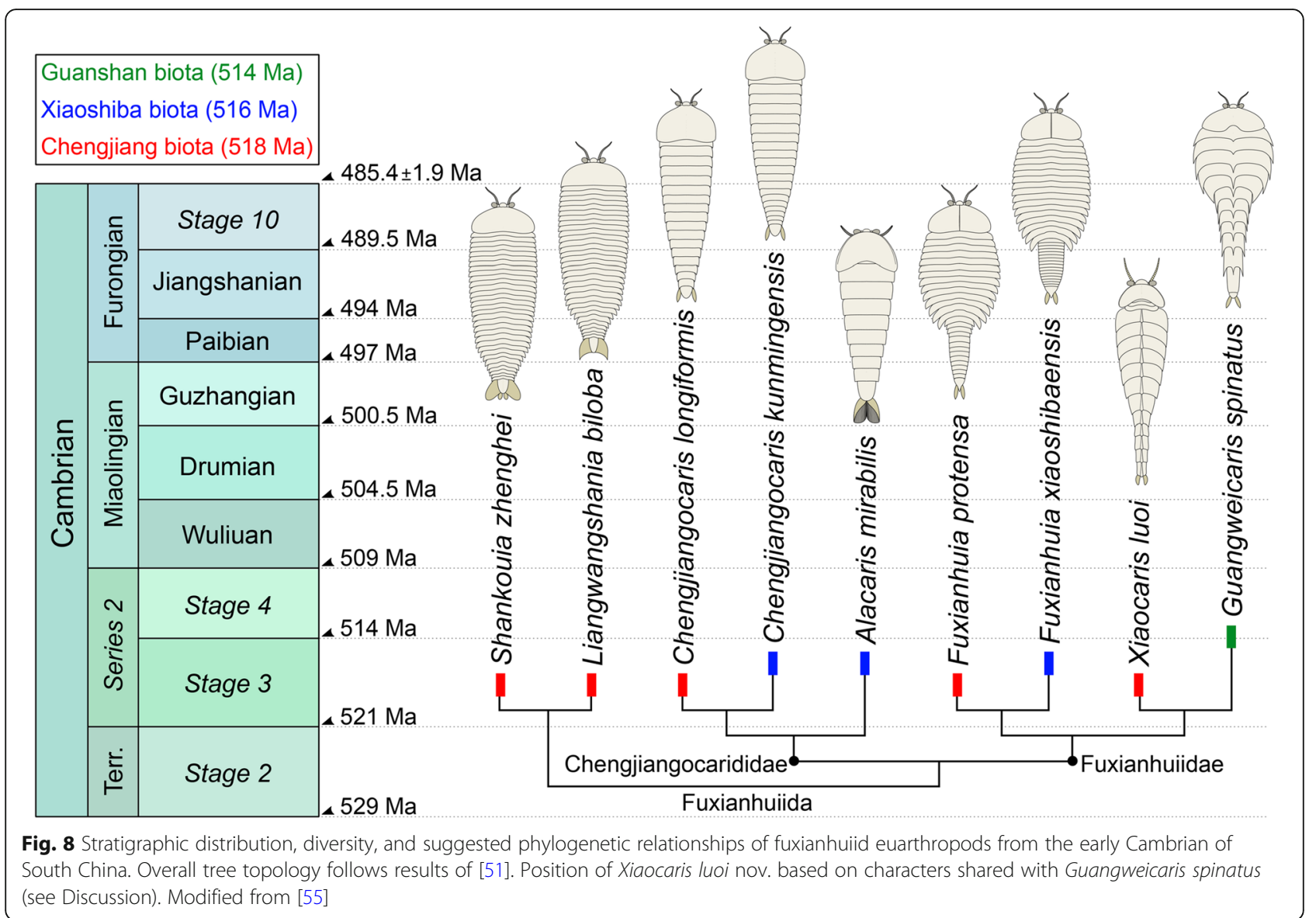

per trunk tergite in Xiaocaris nov., rather than two in Guangweicaris [52]. Notwithstanding these differences, it appears likely that Xiaocaris nov. and Guangweicaris may form a discrete clade within Fuxianhuiidae, as sister taxa to Fuxianhuia species (Fig. 8). Xiaocaris nov. shares some similarities with members of Chengjiangocarididae $[5,21,51,60]$, particularly the subtrapezoidal outline of the trunk tergites with straight tergopleural margins, the presence of up to four appendage pairs per tergite, and a more gradual posterior tapering of the body when compared with Fuxianhuia or Guangweicaris. Xiaocaris nov. specifically resembles Alacaris from the Cambrian (Stage 3) Xiaoshiba biota in overall appearance and in that the procurved posterior margin of the head shield is more pronounced in these taxa compared to all other fuxianhuiids (Fig. 4a, b) [51, 60], but differs in having a lower tergite count. Furthermore, all chengjiangocaridids are distinguished by a head shield with an approximately 1:1 length/width ratio, five anteriormost

Table 1 Comparison between fuxianhuiid species sorted by maximum length in ascending order

\begin{tabular}{|c|c|c|c|c|}
\hline Taxon & Locality/Age & Min. length $(\mathrm{mm})$ & Max. length (mm) & Reference \\
\hline Xiaocaris luoensis nov. & Chengjiang Stage 3 & $\mathrm{~N} / \mathrm{A}$ & 20.5 & This study \\
\hline Fuxianhuia xiaoshibaensis & Xiaoshiba Stage 3 & 28 & 32 & {$[5,51]$} \\
\hline Chengjiangocaris kunmingensis & Xiaoshiba Stage 3 & 17 & 63 & {$[5,59]$} \\
\hline Liangwangshania biloba & Chengjiang Stage 3 & 45 & 66.6 & {$[54]$} \\
\hline Shankouia zhenghei & Chengjiang Stage 3 & 50 & 75 & {$[47]$} \\
\hline Fuxianhuia protensa & Chengjiang Stage 3 & 12 & 80 & {$[21,31]$} \\
\hline Guangweicaris spinatus & Guanshan Stage 4 & 60 & 95 & {$[52,53]$} \\
\hline Chengjiangocaris longiformis & Chengjiang Stage 3 & N/A & ca. 100 & {$[21,47]$} \\
\hline Alacaris mirabilis & Xiaoshiba Stage 3 & 60 & 120 & {$[51,60]$} \\
\hline
\end{tabular}


small tergites, and their endopods have an almost conical outline without developed ventral endites.

\section{Ontogeny and autecology of the smallest fuxianhuiid}

Xiaocaris nov. holds the distinction of being the smallest member of Fuxianhuiida described to date (Table 1). With a total length (sag.) of $20.5 \mathrm{~mm}$ (Fig. 2), Xiaocaris nov. is six times smaller than the largest fuxianhuiid specimens known (e.g. [51]), and only directly comparable to juvenile individuals of Fuxianhuia protensa (see [31]) and Chengjiangocaris kunmingensis (see [5]). Given the substantial size differential, we reaffirm that Xiaocaris nov. represents a distinct genus, rather than a juvenile of another known taxon. For instance, the presence of three anteriormost tergites underneath the head shield makes Xiaocaris nov. only directly comparable with other members of Fuxianhuiidae. In euarthropods with an anamorphic phase of ontogenetic development, metameric segments are produced from a posterior growth zone and released towards the anterior end of the body, so that the segments and (their corresponding tergites) on the anterior half of the trunk will be ontogenetically older than those in the posterior half (e.g. [36, 61-63]). In this context, Xiaocaris nov. can be confidently discarded as a member of Chengjiangocarididae or Shankouia/Liangwangshania since all these forms have five or six anteriormost small segments with reduced trunk tergites that would have been patterned during early development. The drastic differences in size and morphology observed between the small anterior segments with reduced tergites (each associated with one appendage pair), and the larger tergites that constitute most of the trunk (each associated with multiple appendage pairs), suggest an important developmental and temporal shift during body elongation and dorsoventral segmentation in fuxianhuiids. Thus, we argue that the number of anterior reduced tergites represents a phylogenetically and developmentally meaningful character to distinguish between fuxianhuiid taxa, even if these euarthropods share a fundamentally similar overall pattern of trunk tagmosis. Within Fuxianhuiidae, it is also possible to discard the possibility of Xiaocaris nov. as a juvenile of Fuxianhuia thanks to the recent data on the hemianamorphic development of the latter [31]. Fuxianhuia juveniles are morphologically distinct from Xiaocaris nov. in the absence of a recurved posterior head shield margin, no dorsal keel, and differences in the proportions of the head shield and trunk tergites that only become more pronounced throughout Fuxianhuia ontogeny [31]. Finally, despite the close similarity between Xiaocaris nov. and Guangweicaris, these two can still be regarded as separate taxa. Whereas Xiaocaris nov. bears four pairs of biramous appendages per trunk tergite, Guangweicaris only features two pairs per tergite [52,
53]. Likewise, the appendage-less posterior trunk of Xiaocaris nov. presents six narrow tergites, but that of Guangweicaris contains seven. Considering that the trunk of both taxa consists of 15 tergites, it is highly unlikely that the appendages would shift in their number and distribution within the trunk simply as a result of an increase in body size during ontogeny, and particularly without the formation of additional body segments from the posterior end. Although we are restricted in our ability to ascertain whether He-f-6-5-63/64 represents a fully mature adult individual or not, the morphological differences relative to other closely related taxa consolidate its status as a separate fuxianhuiid species.

The preserved functional morphology of Xiaocaris nov. reveals important aspects of its autecology, regardless of its small size and uncertain degree of ontogenetic maturity. The antennae are elongate and most likely had a chemo-tactile sensorial function that was further complemented by the large stalked lateral eyes (e.g. [26]). Well-preserved fuxianhuiids typically possess a pair of specialized post-antennal appendages (SPAs) located posterior to the antennae in a para-oral position, and which appear to have been involved in food manipulation based on their location, degree of motion, and overall robust constitution [5, 51,52]. Although is not possible to observe these appendages in Xiaocaris nov. due to incomplete preservation, He-f-6-5-63/64 reveals instead an important degree of post-oral appendage complexity absent in most other fuxianhuiids. The biramous appendages of Xiaocaris nov. are densely packed throughout the trunk and form a well-defined median food groove that is aligned with the sagittal body axis, and consequently the expected position of the mouth opening underneath the hypostome (Figs. $3 \mathrm{~b}, 6 \mathrm{~b}$ ). Each of the (at least) 15 endopod articles carries a well-developed triangular ventral endite, the latter of which are more robust towards the proximal appendage bases (Fig. 4b, c). There is no clear evidence of a differentiated protopodite as expressed in the anterior appendages of Alacaris mirabilis [51], but the spinose enditic armature of Xiaocaris nov. strongly suggests that the appendages were probably used in coordinated metachronal waves to secure, process and transport food items towards the mouth opening. $\mathrm{Nu}$ merous Cambrian euarthropods feature similar feeding adaptations consisting of well-developed spinose endites directed adaxially to form a median food groove $[38,64]$, which suggests that Xiaocaris nov. was most likely a benthic scavenger. More specifically, we hypothesize that the high degree of appendage spinosity in Xiaocaris nov. would have been better suited for shredding soft food items or organic matter rather than durophagy, as the latter strategy typically requires the presence of a structurally robust and enlarged 
protopodite with strengthened endites for crushing prey [64-66].

The feeding adaptations observed in Xiaocaris nov. set it apart from the post-oral appendage morphology of most fuxianhuiids, which mainly consists of short or elongate endopods with a generally smooth or conical outline, and for the most part lacking in spinose elements (with the exception of Guangweicaris [52, 53];). Fuxianhuiid feeding autecology remains largely obscure, as most representatives either have mostly undifferentiated appendages with the exception of the SPAs (e.g. Fuxianhuia, Chengjiangocaris; see [5, 21, 55, 58, 59]), or the appendages themselves are simply poorly known (e.g. Shankouia/Liangwangshania [47, 54];). For example, a single enigmatic euarthropod from the Wuliuan Kaili Formation has been regarded as a putative fuxianhuiid with preserved gut contents [67], but the affinity of this fossil remains highly dubious owing to its poor preservation. Alacaris mirabilis from the Xiaoshiba biota is the only fuxianhuiid with a differentiated and enlarged protopodite with prominent gnathobasic spines, but only restricted to three pairs of post-oral appendages the anterior end of the body, whereas the endopods through most of the trunk have an almost conical construction with rounded ventral edges [51, 60]. In addition to Alacaris, specimens of Chengjiangocaris from the Xiaoshiba biota demonstrate the presence of minute medially directed spine-like projections on the bases on the post-oral appendages that form a food groove [51], but otherwise the endopods lack well-developed endites suggesting limited food processing capabilities. Earlier studies have pointed that fuxianhuiid guts are commonly filled with sediment, which prompted interpretations that these euarthropods were mainly deposit feeders (e.g. $[21,58])$. However, the recent recognition of a wellpreserved digestive tract with paired midgut diverticulae in Fuxianhuia protensa argues instead for a more complex feeding ecology [25], in line with other Cambrian euarthropods with similar digestive system adaptations for promoting macrophagy, carnivory, and efficient digestion (e.g. [24]). Although He-f-6-5-63/64 lacks information on the organization of the gut, the functional morphology of the biramous appendages is congruent with a macrophagous scavenging habitus, which becomes all the more significant when considering its small size. The differences in the ventral appendage armature observed between Xiaocaris nov. and other larger Chengjiang fuxianhuiids (i.e. Fuxianhuia protensa, Chengjiangocaris longiformis, Shankouia/Liangwangshania) could suggest a degree of niche partitioning based on body size that avoided direct competition for resources between closely related species living in the same environment. A similar pattern, albeit within an ontogenetic context, has been recently recognized for nektobenthic euarthropods from Chengjiang, including the megacheiran Leanchoilia illecebrosa [68], and the trilobitomorph Naraoia spinosa [38], in which juveniles feature different feeding adaptations and autecologies compared to the corresponding adults. Ultimately, the exceptional appendicular data observed in Xiaocaris nov. contribute towards a more complete understanding of fuxianhuiid functional morphology and possible ecological adaptations in the Chengjiang biota.

\section{Fuxianhuiid diversity in early Cambrian deposits from South China}

Xiaocaris nov. brings the number of monospecific fuxianhuiid genera for the Chengjiang biota to five (or four depending on the status of Shankouia/Liangwangshania [54];). Although both Fuxianhuia and Chengjiangocaris have species represented in the stratigraphically younger Xiaoshiba biota, none of the fuxianhuiid-bearing localities in the Yangtze platform have more than one species of any given taxon (Fig. 8; Table 1). Thus, the Chengiiang biota contains the highest species diversity of fuxianhuiid euarthropods to date, followed by the Xiaoshiba biota with three $[5,51]$, and finally the Stage 4 Guanshan biota [52, 53]. Some broad patterns emerge from this temporal distribution. Stratigraphically younger fuxianhuiid species appear to become both less diverse and abundant in their respective localities. This is well exemplified by Fuxianhuia, which is known from hundreds of specimens in the Chengjiang (e.g. [3, 21, $58]$ ), but less so in the Xiaoshiba $[5,6,51]$, and is completely absent from Guanshan. Although Chengjiangocaris is better represented in the Xiaoshiba $[5,59]$ compared to Chengjiang $[3,21]$, this would appear to result from a lack of worker effort as Chengjiangocaris longiformis has not been thoroughly revised in over 20 years [21]. Shankouia/Liangwangshania are endemic to Chengjiang, but lack close relatives in any of the younger deposits based on the results of recent phylogenetic analyses (e.g. [51]). Xiaocaris nov. is unique within the group as it represents the rarest fuxianhuiid described to date, known from a single specimen, but also its closest relative is found in a much younger stratigraphic unit (i.e. Guangweicaris in Guanshan) without any known intermediates in the Xiaoshiba biota (Fig. 8). The discovery of Xiaocaris nov. points towards a more complex evolutionary history of Fuxianhuiida than previously considered, and suggests the existence of cryptic euarthropod species in early Cambrian deposits from the Yangtze platform with great promise for future discoveries through advanced imaging methods.

\section{Conclusions}

We employed micro-CT techniques to restudy the fossil material originally ascribed to the enigmatic Chengjiang 
euarthropod Jianshania furcatus, and revealed previously unknown morphological details of the ventral appendage organization. The holotype of J. furcatus features a semicircular head shield with eye notches, stalked lateral eyes, a body with 11 segments and an elongate tailspine with a distal bifurcation. By contrast, we find that the second specimen initially assigned to J. furcatus represents a separate new taxon altogether, Xiaocaris luoi nov., based on the presence of 15 trunk tergites, including three small anterior segments with reduced tergites that are partially overlain by the head shield in life position. The morphology of the ventral appendages, including the presence of elongate antennae, endopods with 15 articles and robust endites, and multiple biramous appendage pairs under most trunk tergites strongly support fuxianhuiid affinities for $X$. luoi nov. The presence of 15 trunk tergites with a single series of well-developed median tergal processes keel and endopods with robust ventral endites in $X$. luoi nov. supports its sister-group relationship to Guangweicaris spinatus from the upper Guanshan biota. In turn, this phylogenetic relationship suggests a cryptic evolutionary radiation within Fuxianhuiidae. The well-developed endites of $X$. luoi nov. indicate a benthic scavenger mode of life, that most likely fed on soft food items or organic matter. The recognition of Xiaocaris luoi nov. demonstrates the potential of micro-CT to study the exceptionally preserved fossils of Chengjiang and promise for new discoveries. A thorough redescription of the morphology of the Jianshania furcatus holotype is currently in preparation.

\section{Methods}

The studied material consists of two specimens from the Ercaicun section of Haikou, Kunming, Yunnan Province $[12,41]$. Stratigraphically, they belong to the Yu'anshan Member, Chiungchussu Formation (Cambrian Stage 3). These include the Jianshania furcatus holotype, specimen Hz-f-6-307 (Fig. 1), and a second specimen He-f-65-63/64 (Figs. 2, 3, 4) that is herein re-described as a new euarthropod Xiaocaris luoi gen. et sp. nov.

The specimens were photographed under crosspolarized light and fluorescent illumination to document details of the preserved dorsal morphology. Digital photographs were captured with a Nikon D850 DSLR fitted with a $60 \mathrm{~mm}$ Nikkor macro, and fluorescence microscopic images were captured with a Leica DFC7000T CCD linked to a Leica Mz10 F fluorescent microscope. We employed X-ray micro-computed tomography (micro-CT) to study exoskeletal and ventral structures concealed within the rock matrix (e.g. [35-40]). X-ray scanning of the part (Figs. 3 and 5) was performed on a Zeiss X-radia 520 Versa (voltage $60 \mathrm{kV}$, current: $84 \mu \mathrm{A}$, voxel size: $6.59 \mu \mathrm{m}$ ) in the Institute of Geology and Geophysics, Chinese Academy of Sciences. ROI scans of the head and posterior trunk region (Fig. 4) were performed on a Zeiss X-radia 520 Versa (voltage $50 \mathrm{kV}$, current: $80 \mu \mathrm{A}$, voxel sizes: $6.17 \mu \mathrm{m}, 4.49 \mu \mathrm{m})$ at the Yunnan Key Laboratory for Palaeobiology, Yunnan University. Each scan generated a set of radiographs saved as TIFF stacks which were further processed with the Drishti software (version 2.4) [69]. The 3D models rendered in Drishti were screen-captured as images in the figures, and were recorded as videos included in the supplementary material.

\section{Supplementary information}

Supplementary information accompanies this paper at https://doi.org/10. 1186/s12862-020-01625-4.

Additional file 1: Video S1. Dorsal side of Xiaocaris luoi nov. as shown in Fig. 3a.

Additional file 2: Video S2. Ventral side of Xiaocaris luoi nov. as shown in Fig. 3b.

Additional file 3: Video S3. Head of Xiaocaris luoi nov. as shown in Fig. $4 a, b$.

Additional file 4: Video S4. Head of Xiaocaris luoi nov. as shown in Fig. $4 c, d$.

\section{Abbreviations}

ant: Antenna; asc: Anterior sclerite; bt: Bifurcate termination; ed: Endite; en: Endopod; ey: Stalked eye; hs: Head shield; hy: Hypostome; kl: Dorsal keel; ms: Marginal setae; An: The $n$th article; tf: Tail fluke; Tn: The $n$th trunk tergite/ segment; tp: Tailspine

\section{Acknowledgements}

Thanks to Andrew Gehrke and Mansi Srivastava (OEB, Harvard) for facilitating access to fluorescent microscopy equipment, and Runqing Zhou (Institute of Geology and Geophysics, Chinese academy of Sciences) for scanning the part specimen of Xiaocaris luoi nov. We also thank Yunnan Institute of Geological Survey for granting access to both specimens used in this study. Thanks to Giuseppe Fusco, Joachim Haug and an anonymous reviewer for their insightful comments that helped us improve the manuscript.

\section{Authors' contributions}

$\mathrm{YL}$ and $\mathrm{JOH}$ designed the research. $\mathrm{YL}, \mathrm{HC}$, DZ processed micro-CT data and prepared the materials for the figures. $\mathrm{JOH}$ wrote the manuscript with input from the other co-authors, drafted the figures, and prepared the morphological reconstruction. HM scanned the counterpart specimen of Xiaocaris luoi with assistance from DZ. YL, DZ and XH made the specimens accessible. All authors analyzed the data and performed research, and have read and approved the manuscript.

\section{Funding}

This study is supported by Natural Science Foundation of Yunnan Province 2018FA025, 2018IA073 to YL for the lab work, data acquisition and artistic reconstruction painting; Harvard China Fund to $\mathrm{JOH}$ for lab work and manuscript writing; and NSFC 41861134032, Natural Science Foundation of Yunnan Province 2015HA021 and 2019DG050 to XH for data acquisition and analysis

Availability of data and materials

The material is deposited in the Yunnan Institute of Geological Survey (He-f6-5-63/64, Hz-f-6-307a, b). Videos supporting this article have been uploaded as supplementary material.

Ethics approval and consent to participate Not applicable. 


\section{Consent for publication}

Not applicable.

\section{Competing interests}

The authors declare that they have no competing interests.

\section{Author details}

'Yunnan Key Laboratory for Palaeobiology, Institute of Palaeontology, Yunnan University, Kunming 650500, China. ${ }^{2}$ MEC International Joint Laboratory for Palaeobiology and Palaeoenvironment, Yunnan University, Kunming 650500, China. ${ }^{3}$ Museum of Comparative Zoology and Department of Organismic and Evolutionary Biology, Harvard University, 26 Oxford Street, Cambridge, MA 02138, USA.

Received: 4 March 2020 Accepted: 11 May 2020

Published online: 01 June 2020

\section{References}

1. Zhang XL, Liu WD, Zhao YL. Cambrian burgess shale-type Lagerstätten in South China: distribution and significance. Gond Res. 2008;14(1-2):255-62.

2. Fu DJ, Tong GH, Dai T, Liu W, Yang YN, Zhang Y, Cui LH, Li LY, Yun H, Wu Y, Sun A, Liu C, Pei WR, Gaines RR, Zhang XL. The Qingjiang biota-a Burgess Shale-type fossil Lagerstätte from the early Cambrian of South China. Science. 2019:363(6433):1338-42.

3. Hou XG, Siveter DJ, Siveter DJ, Aldridge RJ, Cong PY, Gabbott S, Ma XY, Purnell MA, Williams M. The Cambrian fossils of Chengjiang, China: the flowering of early animal life. Chichester: Wiley; 2017.

4. Sun HJ, Zhao FC, Steiner M, Li GX, Na L, Pan B, Yin ZJ, Zeng H, Van Iten H, Zhu MY. Skeletal faunas of the lower Cambrian Yu'anshan formation, eastern Yunnan, China: metazoan diversity and community structure during the Cambrian age 3. Palaeogeogr Palaeoclimatol Palaeoecol. 2020;542: 109580

5. Yang J, Ortega-Hernández J, Butterfield NJ, Zhang XG. Specialized appendages in fuxianhuiids and the head organization of early euarthropods. Nature. 2013:494(7438):468.

6. Zeng H, Zhao FC, Yin ZJ, Li GX, Zhu MY. A Chengjiang-type fossil assemblage from the Hongjingshao formation (Cambrian Stage 3) at Chenggong, Kunming, Yunnan. Chinese Sci Bul. 2014;59(25):3169-75.

7. Zhang $\mathrm{XL}$, Hua H. Soft-bodied fossils from the Shipai formation, lower Cambrian of the three gorge area, South China. Geol Mag. 2005;142(6):699-709.

8. Hu SX, Zhu MY, Steiner M, Luo HL, Zhao FC, Liu Q. Biodiversity and taphonomy of the early Cambrian Guanshan biota, eastern Yunnan. Sci China Earth Sci. 2010;53(12):1765-73.

9. Liu Q, Lei Q. Discovery of an exceptionally preserved fossil assemblage in the Balang formation (Cambrian series 2, Stage 4) in Hunan, China. Alcheringa. 2013;37(2):269-71.

10. Zhao YL, Yuan JL, Babcock LE, Guo QJ, Peng J, Yin LM, Yang XL, Peng SC, Wang CJ, Gaines RR, Esteve J, Tai TS, Yang RD, Wang Y, Sun HJ, Yang YN. Global standard Stratotype-section and point (GSSP) for the conterminous base of the Miaolingian series and Wuliuan stage (Cambrian) at Balang, Jianhe, Guizhou, China. Episodes. 2019:42(2):165-83.

11. Zhu XJ, Peng SC, Zamora S, Lefebvre B, Chen GY. Furongian (upper Cambrian) Guole Konservat-Lagerstätte from South China. Acta Geol Sin English Edition. 2016;90(1):30-7.

12. Han J, Shu DG, Zhang ZF, Liu JN, Zhang X, Yao Y. Preliminary notes on softbodied fossil concentrations from the early Cambrian Chengjiang deposits. Chin Sci Bull. 2006;51(20):2482-92.

13. Gaines RR. Burgess Shale-type preservation and its distribution in space and time. Paleontol Soci Papers. 2014;20:123-46.

14. Butterfield NJ. Leanchoilia guts and the interpretation of three-dimensional structures in Burgess Shale-type fossils. Paleobiology. 2002;28(1):155-71.

15. Gabbott SE, Hou XG, Norry MJ, Siveter DJ. Preservation of early Cambrian animals of the Chengjiang biota. Geology. 2004;32(10):901-4

16. Hendricks JR, Lieberman BS, Stigall AL. Using GIS to study palaeobiogeographic and macroevolutionary patterns in soft-bodied Cambrian arthropods. Palaeogeogr Palaeoclimatol Palaeoecol. 2008, 264(1-2):163-75

17. Caron JB, Gaines RR, Aria C, Mángano MG, Streng M. A new phyllopod bedlike assemblage from the Burgess Shale of the Canadian Rockies. Nat Commun. 2014;5:3210.
18. Lerosey-Aubril R, Gaines RR, Hegna TA, Ortega-Hernández J, Van Roy P, Kier C, Bonino E. The Weeks formation Konservat-Lagerstätte and the evolutionary transition of Cambrian marine life. J Geol Soci. 2018;175(5):705-15.

19. Harper DA, Hammarlund EU, Topper TP, Nielsen AT, Rasmussen JA, Park TYS, Smith MP. The Sirius Passet Lagerstätte of North Greenland: a remote window on the Cambrian explosion. J Geol Soci. 2019;176:1023-37.

20. Paterson JR, García-Bellido DC, Jago JB, Gehling JG, Lee M, Edgecombe GD. The Emu Bay shale Konservat-Lagerstätte: a view of Cambrian life from East Gondwana. J Geol Soc. 2016:173(1):1-11.

21. Hou XG, Bergström J. Arthropods from the lower Cambrian Chengjiang fauna, Southwest China. Fossils Strata. 1997:45:1-116.

22. Steiner M, Zhu MY, Zhao YL, Erdtmann BD. Lower Cambrian Burgess Shaletype fossil associations of South China. Palaeogeogr Palaeoclimatol Palaeoecol. 2005;220(1-2):129-52.

23. Bergström J, Hou XG, Hålenius U. Gut contents and feeding in the Cambrian arthropod Naraoia. GFF. 2007;129(2):71-6.

24. Vannier J, Liu J, Lerosey-Aubril R, Vinther J, Daley AC. Sophisticated digestive systems in early arthropods. Nat Commun. 2014;5:3641.

25. Ortega-Hernández J, Fu D, Zhang XL, Shu DG. Gut glands illuminate trunk segmentation in Cambrian fuxianhuiids. Curr Biol. 2018;28(4):R146-7.

26. Ma XY, Hou XG, Edgecombe GD, Strausfeld NJ. Complex brain and optic lobes in an early Cambrian arthropod. Nature. 2012;490(7419):258.

27. Tanaka G, Hou XG, Ma XY, Edgecombe GD, Strausfeld NJ. Chelicerate neural ground pattern in a Cambrian great appendage arthropod. Nature. 2013; 502(7471):364.

28. Cong PY, Ma XY, Hou XG, Edgecombe GD, Strausfeld NJ. Brain structure resolves the segmental affinity of anomalocaridid appendages. Nature. 2014 513(7519):538.

29. Hou XG, Clarkson EN, Yang J, Zhang XG, Wu G, Yuan Z. Appendages of early Cambrian Eoredlichia (Trilobita) from the Chengjiang biota, Yunnan, China. Earth Environ Sci Trans R Soc Edinb. 2008;99(3-4):213-23.

30. Duan $Y$, Han J, Fu DJ, Zhang $X L$, Yang $X$, Komiya $T$, Shu DG. Reproductive strategy of the bradoriid arthropod Kunmingella douvillei from the lower Cambrian Chengjiang Lagerstätte, South China. Gond Res. 2014;25(3):983-90.

31. Fu DJ, Ortega-Hernández J, Daley AC, Zhang XL, Shu DG. Anamorphic development and extended parental care in a 520 million-year-old stemgroup euarthropod from China. BMC Evol Biol. 2018;18(1):147.

32. Edgecombe GD, Ramsköld L. Relationships of Cambrian Arachnata and the systematic position of Trilobita. Journal of Paleotol. 1999:73(2):263-87.

33. Chen JY, Waloszek D, Maas A. A new 'great-appendage' arthropod from the lower Cambrian of China and homology of chelicerate chelicerae and raptorial antero-ventral appendages. Lethaia. 2004;37(1):3-20.

34. Cong PY, Edgecombe GD, Daley AC, Guo J, Pates S, Hou XG. New radiodonts with gnathobase-like structures from the Cambrian Chengjiang biota and implications for the systematics of Radiodonta. Papers Palaeontol. 2018:4(4):605-21.

35. Liu Y, Scholtz G, Hou XG. When a 520 million-year-old Chengjiang fossil meets a modern micro-CT - a case study. Sci Rep. 2015:5:12802.

36. Liu Y, Melzer RR, Haug JT, Haug C, Briggs DE, Hörnig MK, He YY, Hou XG. Three-dimensionally preserved minute larva of a great-appendage arthropod from the early Cambrian Chengjiang biota. Proc Natl Acad Sci. 2016:113(20):5542-6.

37. Zhai DY, Ortega-Hernández J, Wolfe JM, Hou XG, Cao C, Liu Y. Three dimensionally preserved appendages in an early Cambrian stem-group pancrustacean. Curr Biol. 2019;29(1):171-7.

38. Zhai DY, Edgecombe GD, Bond AD, Mai HJ, Hou XG, Liu Y. Fine-scale appendage structure of the Cambrian trilobitomorph Naraoia spinosa and its ontogenetic and ecological implications. Proc R Soc B Biol Sci. 2019; 286(1916):20192371.

39. Zhai DY, Williams M, Siveter DJ, Harvey THP, Sansom RS, Gabbott SE, Siveter DJ, Ma XY, Zhou RQ, Liu Y, Hou XG. Variation in appendages in early Cambrian bradoriids reveals a wide range of body plans in stemeuarthropods. Commun Biol. 2019;2:329.

40. Chen XH, Ortega-Hernández J, Wolfe JM, Zhai DY, Hou XG, Chen AL, Mai HJ Liu Y. The appendicular morphology of Sinoburius lunaris and the evolution of the artiopodan clade Xandarellida (Euarthropoda, early Cambrian) from South China. BMC Evol Biol. 2019:19(1):165.

41. Luo HL, Hu SX, Chen LZ, Zhang SS, Tao YH. Early Cambrian Chengjiang Fauna From Kunming Region China. Kunming: Yunnan Science and Technology Press [in Chinese]; 1999. 
42. Chen LZ, Luo HL, Hu SX, Yin J, Jiang ZW, Wu Z, Li F, Chen A. Early Cambrian Chengjiang fauna in eastern Yunnan, China. Kunming: Yunnan Science and Technology Press [in Chinese]; 2002.

43. Lankester ER. The structure and classification of Arthropoda. Quart J Micros Sci. 1904; $47: 523-32$.

44. Ortega-Hernández J. Making sense of 'lower'and 'upper'stem-group Euarthropoda, with comments on the strict use of the name Arthropoda von Siebold, 1848. Biol Rev. 2016;91(1):255-73.

45. Bousfield EL. A contribution to the natural classification of lower and middle Cambrian arthropods: food gathering and feeding mechanisms. Amphipacifica. 1995;2(1):3-34.

46. Chen AL. A new Fuxianhuia-like arthropod of the early Cambrian Chengjiang fauna in Yunnan. Yunnan Geology. 2005;24:108-13.

47. Waloszek D, Chen JY, Maas A, Wang XQ. Early Cambrian arthropods-new insights into arthropod head and structural evolution. Arthropod Struct Dev. 2005;34(2):189-205.

48. Hou XG. Three new large arthropods from lower Cambrian, Chengjiang, eastern Yunnan. Acta Palaeontol Sinica. 1987;26(3):272-85.

49. Luo HL, Fu X, Hu SX, Li Y, Hou S, You T, Pang J, Liu Q. A new arthropod, Guangweicaris Luo, Fu et Hu gen. Nov. from the early Cambrian Guanshan Fauna, Kunming, China. Acta Geol Sin. 2007;81:1-7.

50. Hou XG, Bergström J. The arthropods of the Lower Cambrian Chengjiang fauna, with relationships and evolutionary significance. 179-187. In: Simonetta AM, Conway-Morris S, editors. The Early Evolution of Metazoa and the Significance of Problematic Taxa, vol. 296. Cambridge: Cambridge University Press; 1991.

51. Yang J, Ortega-Hernández J, Legg DA, Lan T, Hou JB, Zhang XG. Early Cambrian fuxianhuiids from China reveal origin of the gnathobasic protopodite in euarthropods. Nat Commun. 2018;9(1):470.

52. Chen H, Legg DA, Zhai DY, Liu Y, Hou XG. New data on the anatomy of the fuxianhuiid arthropod Guangweicaris spinatus from the lower Cambrian Guanshan biota. Yunnan: China. Acta Palaeontol Pol; 2020. [accepted].

53. Wu Y, Liu JN. Anatomy and relationships of the fuxianhuiid euarthropod Guangweicaris from the early Cambrian Guanshan biota in Kunming, Yunnan, Southwest China revisited. Acta Palaeontol Pol. 2019;64(3):543-8.

54. Chen $A L$, Chen $H$, Legg DA, Liu Y, Hou XG. A redescription of Liangwangshania biloba Chen, 2005, from the Chengjiang biota (Cambrian, China), with a discussion of possible sexual dimorphism in fuxianhuiid arthropods. Arthropod Struct Dev. 2018;47(5):552-61.

55. Ortega-Hernández J, Yang J, Zhang XG. Fuxianhuiids. Curr Biol. 2018;28(13): R724-5.

56. Ortega-Hernández J. Homology of head sclerites in Burgess Shale euarthropods. Curr Biol. 2015;25(12):1625-31.

57. Yang J, Hou XG, Dong W. Restudy of Guangweicaris Luo, Fu et Hu, 2007 from the lower Cambrian Canglangpu formation in Kunming area. Acta Palaeontol Sin. 2008:47(1):121.

58. Bergström J, Hou XG, Zhang XG, Clausen S. A new view of the Cambrian arthropod Fuxianhuia. GFF. 2008;130(4):189-201.

59. Yang J, Ortega-Hernández J, Butterfield NJ, Liu Y, Boyan GS, Hou JB, et al. Fuxianhuiid ventral nerve cord and early nervous system evolution in Panarthropoda. Proc Natl Acad Sci. 2016;113(11):2988-93.

60. Yang J, Ortega-Hernández J, Drage HB, Du KS, Zhang XG. Ecdysis in a stem-group euarthropod from the early Cambrian of China. Sci Rep. 2019;9(1):1-9.

61. Hughes NC. The evolution of trilobite body patterning. Annu Rev Earth Planet Sci. 2007;35:401-34

62. Brena C, Akam M. An analysis of segmentation dynamics throughout embryogenesis in the centipede Strigamia maritima. BMC Biol. 2013;11(1):112.

63. Hopkins MJ. Development, trait evolution, and the evolution of development in trilobites. Inte and Comp Biol. 2017;57(3):488-98.

64. Bicknell RD, Paterson JR, Caron JB, Skovsted CB. The gnathobasic spine microstructure of recent and Silurian chelicerates and the Cambrian artiopodan Sidneyia: functional and evolutionary implications. Arthropod Struct Dev. 2018;47(1):12-24.

65. Zacaï A, Vannier J, Lerosey-Aubril R. Reconstructing the diet of a 505million-year-old arthropod: Sidneyia inexpectans from the Burgess Shale fauna. Arthropod Struct Dev. 2016;45(2):200-20.

66. Bicknell RD, Ledogar JA, Wroe S, Gutzler BC, Watson WH III, Paterson JR. Computational biomechanical analyses demonstrate similar shell-crushing abilities in modern and ancient arthropods. Proc R Soc B Biol Sci. 2018; 285(1889):20181935.
67. Zhu MY, Vannier J, Iten HV, Zhao YL. Direct evidence for predation on trilobites in the Cambrian. Proc R Soc B Biol Sci. 2004;271(suppl_5): S277-S80.

68. Liu Y, Haug JT, Haug C, Briggs DE, Hou XG. A 520 million-year-old chelicerate larva. Nat Commun. 2014;5:4440.

69. Limaye A. Drishti: a volume exploration and presentation tool. Version 2.4 [software]. 2012 Oct 17 [cited 2019 Apr. 4]. Available from: https://github. com/nci/drishti/releases/tag/v-2.4-win. 2012.

\section{Publisher's Note}

Springer Nature remains neutral with regard to jurisdictional claims in published maps and institutional affiliations.
Ready to submit your research? Choose BMC and benefit from:

- fast, convenient online submission

- thorough peer review by experienced researchers in your field

- rapid publication on acceptance

- support for research data, including large and complex data types

- gold Open Access which fosters wider collaboration and increased citations

- maximum visibility for your research: over $100 \mathrm{M}$ website views per year

At BMC, research is always in progress.

Learn more biomedcentral.com/submissions 